probably the resulting extension which produces the effect. But $w h \geqslant n$ a tube is exposed to pressure froin the interi or there is dilatation of the walls, which aids the shear. Thus we see why a thin tube is so mach more capable of resisting external than internal pressure. It $i$ is probable that, in the case of glass, the element which first gives way is not so much cru-hed as torn asunder. If so, the tube which is conpressed from with out is in a much more fav urable condition for resisting than that in which the presiure is ajplied internally. For, in the first, the whole substance of the walls is com resed, and thus the linear extension produced by the shear is in part counteracted. In the secont, the whole substance is expa ided, and th s linear exten. sion due to the shear is aided. As will be seen in Appendix A, the case of very thick tubes is considerably different.

X. Description of the Apparatus for applying P'ressure.-Sir Wyville Thomson handed over to me, with the thermometer:, a press which was ma ie for him before he started in the Challenger, and which he had carried all round the worid; but when we made some preliminary experiments with it, we found it to be objectionable in miny ways. It was in the first place not safe at high pressures, althou sh an atceinp: hid been made to strengthen it by surrounding it with massive rings of Swedish iro:l. As the experiments had to be condusted in c.lleye, and to a great extent by students who volunteered their service; this was a fatal defect; though I believe that the danger from the bursting of a hydrostatic presi has been uiu illy very much exargerated. The bursting of the cylinder itself wou'd probably be unattended with danger; but so ne of the nuts a'd connecting pieces had occasionally been projected with great violence.

A slight numerical calculation shows that a cubic foot of water at a pressure of one ton weight to the square inch is capable of doing only about 12 Io foot lbs, of work in expanding, the reas on being that althour the pressure is intense, the amuunt of c.smpression it produces is exceedingly sinall. But a cubic fost of air at a pressure of a ton weight to the square inch is capable of doing nearly 1300 times as mush work in exp.ndiny. Hence the danger of having large quantitics of air in the press before the compression is begun.

An:ther defect of the ap;aratus was the comparatively small interior bore, which did $n$ st admit of the proper carrying out of my scheme for mea iuring pressures - the Bourdon ginuge hiving sh swn itself quite untrustiworthy. Besides, two therinometers, at most, could be exposed to pressure simultane susly, cven whe no gauge was inserted along with then

The apparatu; which Sir Wyville Thomion finally obtained from the Woolwich gun factorie, throu sh the intervention of the $\Lambda$ dmiralty, wa; in fact a Fraer gu i with a few adaltations made $t: s$ suit it to the purposes of the investigation. The gun wa; made of a cylinder of mild steel, round which were shrunk two succes ive wrought-iron c sils. The effective interior is $4 \frac{1}{2}$ inches in bore, and ne rrly 4 feet lon $r$.

This cylinder was graranteed to be safe under pressures up to 18 or 20 tons weight per square inch, and we have for various purposes already worked up to pre isures of $I 1$ and 12 tons.

The rest of the apparatus, to fit it for our immediate purpose, c.nnsisted of a tightly-fitting steel plug which was forced int: the upper end of the cylinder after the thermometers and other apparatu: had been in erted, an 1 the whole had been filled with water. The plug was forced down by the weight of an assistant standing on it, while a stop.cock at the b)ttom of the cylinder was kept open for the escape of water, until a massive steel key could be put in through a sl st in the side of the cylinder to lock the pluy in its definite position.

To the lower end of the steel cylinder were adapted a series of fittings by mean; of which it could be connecte l witb a powerful force-pump, and simultaneously with a gauge whose construction will be afterwardi describel. The gauge enabled the experimenteri to know at every stage of the operation what amount of pressure bad been renched in the interior of the cylinder. 'The pump was worked at first by hand. Of late a more powerful pump has been procured, and it can be fitted when necessary to the gas-engine of my laboratory.

Only one real difficulty was met with in working this apparatus ; viz. the difficulty of making the plug fit perfectly tight. At first, when it came from Woolwich, the plug was finished by a piece of leather in the form of a cup; but this was found to leak seriously even at very moderate pressures, so that even the comparatively small pressure of a ton weight per square inch was unattainable.

But by taking off the leather from the plug and furnishing it with a ring of steel turned into cup form with an exceedingly thin and sharp ed ,e, o. the sume p:inci le a; that on which the piston of the pump wa; co.1 tructel, this diffi sulty wa : c snpletely gut ,ver. The flexible steel ed se was presied against the interior of the tu'se $m$ sre forcibly the greater the applied presisure, and it was found that the ap,aratu; was then, except under the most unfavourable circimstances, perfectly tight, at least so far as the plug was concerned. Very great cure wa, however, requisite in cleaning the plug ant the upper part of the $b$ re of the cylinder befure each experiment. The smullest fra rment of cotton-waste, getting behind the elge of the cup, almost invariably produced seriou; le ak age when high pressure was applied. The cup form was objectionable for one reason, that it always took down a c.msiderable quuntity of air, of which it was im so ssible to get rid. This difficulty was overc me by putling into the cup a quantity of tall ww which comoletely filled it us and projected c.onsiderably bel w it, so that the aipparatu;, when pressure commenced, contained at the most a few small air bubbles only.

Later, when I found it was impossible t) obt rin certain nece;sary data, on account of the sl wne is with which pressure was got up in so large an app uratu;, I procured a very much smaller apparatus of simil ur character, in which the cylinder was only an inch in $b$ re, and rather less than a foot in effective interior length. With thi; appuratu; tws or three stroke; only, of the puinp were required $t$, get $u$, the desired presiure, an't there wa; the grest addition al advant ige that teanperatures could be inde,en lently measure l by mean; of ther.m relectric junctions. [This $\mathrm{c}$ suld not be do:e in the larye cylinder withou: seriou:ly affecting its strength, and rendering it at the same time almost unmanageable.]

( $T o$ be continued.)

\section{TRANSFORMATION OF OLD COINS IN A \\ LAKE}

M DAUBRÉE rea 1 an interestin y paper on this su'pject at the Pari; Academy of Science; on Ostober 17.

In the csmmune of Flines-le:-Roches, canton of Douai, there is a snall lake of very limpid water, known as the Mer-deFlines. It is of circular shape, ant about $300 \mathrm{~m}$. in dianeter; its surface remains stationary in position, and neither s rings supplying it, $\mathrm{n}$ )r any outlet, are apparent. The depth at the centre has not been ditermined. Thore are fishes in the lake, and the water attracts numerous bather:. Amony other shell; on the banks, one observes many specimens of Unit. The water rests on Tertiary strata of the Landenian formation, consisting of sand and gravel, with dark ashes and pyrites.

According to the researches of MM. Terinink and Loustan, this lake appears to have been, in ancient time;, a place of sacred resort, and varions precious objects we:e thrown into it, as an offering doubtless to some divinity. Numerou; coins, more especially, havc been recovered, along with statuettes of bronze and much pottery dibris. Of the coins, some are Gaulish, but the majority are Roman, of the time of the early Empire. They are mostly bronze, but some are of gold.

Some remarkable change; have occurre 1 in many of these coin:, and have been brought to the notice of the French Academy by M. Daubrée. The coin; have been attacked and are completely enveloped with a crystalline substance formed at their cxpense. Their general aspect recalls that of the coins incrusted with metallic mineral; , found in various thermal springs, notably at Bagnères-de-Bigorse, at Bourbonne-les-Bains, and at Baracci in Corsica.

An cxtremely fine external pellicle, of the brass-yellow colour which characterises chalcopyrite, first attracts notice. But the incrustation is mostly formed, to a depth of $2 \mathrm{~mm}$., of a dark crystalline substance, with metallic lustre, consisting of sulphide of copper, and it is to it that the crystalline forms belong, which one might be apt, at first sight, to attribute to yellow sulphur.

The central part consists of a laminated substance. Here and there may be observed small dark hexagonal metallic crystali, in which one can see the characteristic strix of chalcocitc. The same substance forms small brilliant leave;, alternating with the dark leaves, on which appear some deposits of bright green. Heated in 2 tube, the crystalline substance gives a very slight sublimate of sulphur, which apparently results from the mixture of a little pyrites. The sulphide contain's neither tin nor zinc.

The form of the exterior substance is that of hexagonal plates. bearing truncated pyramidal faces inclined about $127^{\circ}$ to the base. The cleavage is basic. This latter character and the 
absence of macles appear to indicate the variety of chalcucite called cuprein by Breithaupt.

All these coins were buried in a dark brown mud, containing numerous shells, many of which have been involved in the sul. phurated deposits. From analysis of a sample of the water obtained at $6.70 \mathrm{~m}$. depth, it appears that, as in the thermal springs above referred to, there are no sulphides, but merely sulphates, which organic matters reduce to the state of sulphides.

The novelty in production of the chalcocite in question arises from its occurrence apart, seemingly, from thermal springs, and at a lower temperature than in the cases hitherto known.

\section{OUR ASTRONOMICAL COLUMN}

The Great Comet of 1861.-The long series of observations of this splendid comet has been very ably discussed, with the view to the determination of the most probable orbit, by Heinrich Kreutz, a pupil of Prof. Schönfeld of Bonn, and the investigation is made the subject of an inaugural dissertation in July, 1880.

The comet was discovered on May 13 by Mr. John Tebbutt of Windsor, N.S.W., but the first accurate observations for position were made at the Observatory of Sydney on May 26. On June Io it was observed at Santiago di Chile, and on the following day at Rio de Janeiro. European observations commenced on June 30, and were continued until May I, I862, the later places being obtained by M. Otto Struve with the 15 -inch refractor at Pulkowa : the comet was not followed at other observatories beyond February 3, when Prof. Julius Schmidt last observed it at Athens. The number of separate observation collected for the determination of the orbit exceeds 1150 , and these extend, as will be seen, over a period of $11 \frac{1}{2}$ months, in which the comet traversed an orbital arc of more than $155^{\circ}$. Seeling's ellipse (period 419 years) is adopted in the calculation of an accurate ephemeris for the whole extent of visibility, and the observations, freed from the effects of parallax and aberration, are compared with this ephemeris for the formation of normal places. The best available positions of the comparison-stars were previously brought to bear upon the observations, so that they have received at the hands of $M$. Kreutz a general revision and rectification, proportional weights being applied after a criticism of the observations at the different observatories, forty-one in number. Thus thirty-one normal positions between 1861, May 28, and 1862, April 23, were formed. The next step was the calculation of the planetary perturbations for the whole interval, and it was found that the attraction of Venus, the Earth, Jupiter, and Saturn were alone sensible; June 12 was taken for the commencement of the perturbations. The normal places being corrected for their elfect, sixty-two differential equations were formed, and their solution by the method of least squares gave the definitive corrections required by Seeling's orbit, which it may be stated proved sufficiently near the truth to render provisional correction unnecessary. The orbit which the comet was describing on June 12 , or about the perihelion-passage in 1861 , is thus found to be as follows:-

\section{Definitive Elements of the Great Comet of 186i.}

Perihelion passage, I861, June II'543949 M.T. at Berlin.

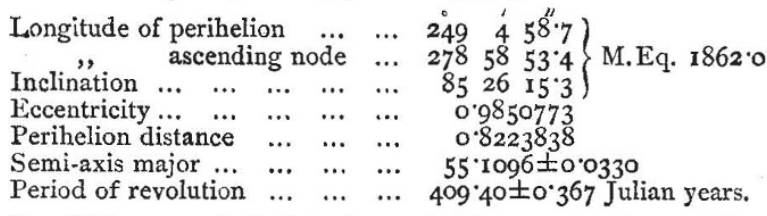

It will be remarked that the probable error of the resulting period is strikingly small.

M. Kreutz defers for the present an examination of the possible effects of planetary perturbation during the last revolution, in view of identifying the comet amongst those observed in the fifteenth century. If, however, the perihelion passage occurred in the winter it is by no means certain that the comet would be sufficiently conspicuous and favourably placed to be remarked in Europe. The following figures will afford an idea of the difficulty that would attend observations in these latitudes during the winter season. Assuming the comet to have been in perihelion twenty days earlier we have these positions for the respective dates (Eq. of 1861 ) :-

\begin{tabular}{|c|c|c|c|c|c|c|c|c|}
\hline & & R.A. & & Decl. & & $\begin{array}{l}\text { istance } \\
\text { n Earth }\end{array}$ & & $\begin{array}{l}\text { Intensity } \\
\text { of light. }\end{array}$ \\
\hline 20 & ․ & $239^{\circ} 7$ & $\ldots$ & -173 & $\ldots$ & I.53 & $\ldots$ & 0.52 \\
\hline Nov. 20 & $\ldots$ & $257^{\circ} \circ$ & $\ldots$ & $-20 \cdot 2$ & $\ldots$ & I.77 & $\ldots$ & 0.39 \\
\hline Dec. 20 & $\ldots$ & $274^{\circ} \mathrm{I}$ & $\ldots$ & -20.8 & $\ldots$ & 1.88 & $\ldots$ & 0.35 \\
\hline $\operatorname{Jan} .20$ & $\ldots$ & $291^{\circ} 5$ & $\ldots$ & -19.3 & $\ldots$ & I 86 & $\ldots$ & 0.36 \\
\hline Feb. 20 & . & $308^{\circ} 5$ & $\ldots$ & -15.8 & $\ldots$ & I'70 & $\ldots$ & 0.42 \\
\hline
\end{tabular}

In $186 \mathrm{r}$, when the comet appeared as bright as a star of 4.5 mag., the intensity of light was $x^{\cdot} \mathbf{5}$, and it was just perceptible to the naked eye, when the intensity had descended to 0.4 , but there was still a tail of $2 \frac{1}{2}$ degrees to distinguish it from a star, which would hardly be the case in the winter.

The Satellites of Mars. - In No. 2934 of the Astronomische Nachrichten, Prof. Asaph Hall has given data for ephemerides of the satellites of Mars at the opposition of $188 \mathrm{r}$. The N.W. elongations take place with the following values of $u$, corresponding to the argument of latitude :-

$$
\begin{aligned}
& \text { Nov. } 22 \quad \cdots \quad 33^{\circ} \cdot 7 \mid \begin{array}{llll|lll} 
& \text { Dec. } 4 & \cdots & 33^{\circ} \cdot 3 & \text { Dec. I6 } & \ldots & 327^{\circ} \cdot \mathrm{I}
\end{array}
\end{aligned}
$$

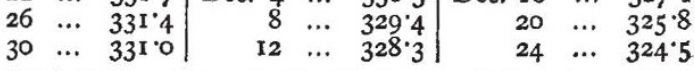

From Prof. Hall's values of $u$ it will be found that true N.W. elongations of Deimos occur Nov. $26^{\circ} 44_{11}$, Dec. I 4886 , Dec. 6.5350 , and S.E. elongations Nov. $24^{\circ} 5480$, Nov. $28 \cdot 3340$, Nov. 29.5957 , and Dec. 3.3793 Greenwich times. On November 26 the distance of Deimos from the centre of the primary at elongation is $48^{\prime \prime} \%$.

\section{UNIVERSITY AND EDUCATIONAL INTELLIGENCE}

CAMBridge,-The last report of the Higher Local Examinations shows that in Group E (Natural Science subjects) there was a falling off of ten candidates and of two first classes this year. The examiners in Geology and Zoology give a generally favourable report. In Chemistry the practical work done was inferior, and common simple salts were not known by sight. Physiological Botany was little known; and the same remarks applied to Histology in the paper on Animal Physiology. In Group D, Political Economy showed much success, especially among some of the better candidates.

Dr. Latham and Mr. D. McAlister have been appointed members of the State Medicine Syndicate; and Mr. McAlister has been also appointed a member of the Board of Medical Studies.

\section{SOCIETIES AND ACADEMIES LONDON}

Linnean Society, November I 7.-Sir J. Lubbock, Bart., in the chair.-Sir John Kirk, K.C.M.G., was elected a Councillor, and $\mathrm{Mr}$. Frank Crisp Treasurer, in place of $\mathrm{Mr}$. F. Currey, deceased. - Mr. George Murray exhibited (for Col. Turberville), a bough of Pinus pinaster, with suppressed internodes of the lateral branches, the result of injury to the axis from which they sprang.-De Francis Day showed examples of the stomach of the pilchard, with special reference to points in their digestion. Within the pyloric division of the stomach a membranous envelope incloses the food, the latter composed of the Zoëa stage of crustaceans. What peculiar function the sausage-shaped nerves serves in the economy of digestion is uncertain. - Mr. R. J. Lynch exhibited and read a short note on the contrivance for self-fertilisation in Roscoea purpurea, which to some extent resembles that of Salvia by modifications of anther and filament.-Sir John Lubbock, Bart., then read his ninth communication on the habits of ants, bees, and wasps. He detailed experiments proving that bees prefer blue flowers to those of other colours. But again if bees have so much to do with the origin of flowers, how is it there should be so comparatively few blue ones? Sir John suggests that all flowers were originally green, and then passed through white or yellow, and generally red, before becoming blue. Ants, he stated, may live seven or ejght years.-Mr. C. B. Clarke described a Hampshire orchis not represented in English botany. This pale, flesh-coloured, or yellow orchis he demonstrates is the true $O$. incarnata, Linn., and not that figured by Syme and Babington, which is the O. latifolia, Linn. -Prof. Cobbold described a new entozoon from the ostrich, named by him Strongylus Douglasii. It is said to prove de- 